\title{
Human osteochondritis dissecans fragment-derived chondrocyte characteristics ex vivo, after monolayer expansion-induced de-differentiation, and after re-differentiation in alginate bead culture
}

\author{
Matthias Aurich ${ }^{1,2,3}$, Gunther O. Hofmann², Florian Gras ${ }^{2}$ and Bernd Rolauffs ${ }^{4,5^{*}}$
}

\begin{abstract}
Background: Autologous chondrocyte implantation (ACI) is a therapy for articular cartilage and osteochondral lesions that relies on notch- or trochlea-derived primary chondrocytes. An alternative cell source for $\mathrm{ACl}$ could be osteochondritis dissecans (OCD) fragment-derived chondrocytes. Assessing the potential of these cells, we investigated their characteristics ex vivo and after monolayer expansion, as monolayer expansion is an integral step of ACl. However, as monolayer expansion can induce de-differentiation, we asked whether monolayer-induced de-differentiation can be reverted through successive alginate bead culture.
\end{abstract}

Methods: Chondrocytes were isolated from the OCD fragments of 15 patient knees with ICRS grades 3-4 lesions for ex vivo analyses, primary alginate bead culture, monolayer expansion, and alginate bead culture following monolayer expansion for attempting re-differentiation. We determined yield, viability, and the mRNA expression of aggrecan and type I, II, and X collagen.

Results: OCD fragment-derived chondrocyte isolation yielded high numbers of viable cells with a low type l:Il collagen expression ratio $(<1)$ and a relatively high aggrecan and type $I I$ and $X$ collagen mRNA expression, indicating chondrogenic and hypertrophic characteristics. As expected, monolayer expansion induced de-differentiation. Alginate bead culture of monolayer-expanded cells significantly improved the expression profile of all genes investigated, being most successful in decreasing the hypertrophy marker type $X$ collagen to $1.5 \%$ of its ex vivo value. However, the chondrogenic phenotype was not fully restored, as the collagen type l:Il expression ratio decreased significantly but remained $>1$.

Conclusion: OCD fragment derived human chondrocytes may hold not yet utilized clinical potential for cartilage repair.

Keywords: Chondrocyte, Articular cartilage, De-differentiation, Re-differentiation, Monolayer expansion, Alginate bead culture

\footnotetext{
* Correspondence: berndrolauffs@googlemail.com

${ }^{4}$ G.E.R.N. Tissue Replacement, Regeneration \& Neogenesis, Department of Orthopedics and Trauma Surgery, Medical Center - Albert-Ludwigs-University of Freiburg, Faculty of Medicine, Albert-Ludwigs-University of Freiburg, Hugstetter Straße 55, 79106 Freiburg, Germany

${ }^{5}$ Massachusetts Institute of Technology, Center for Biomedical Engineering,

500 Technology Sq, Cambridge, MA 02139, USA

Full list of author information is available at the end of the article
}

(c) The Author(s). 2018 Open Access This article is distributed under the terms of the Creative Commons Attribution 4.0 International License (http://creativecommons.org/licenses/by/4.0/), which permits unrestricted use, distribution, and reproduction in any medium, provided you give appropriate credit to the original author(s) and the source, provide a link to the Creative Commons license, and indicate if changes were made. The Creative Commons Public Domain Dedication waiver (http://creativecommons.org/publicdomain/zero/1.0/) applies to the data made available in this article, unless otherwise stated. 


\section{Background}

Articular cartilage (AC) provides a low-friction interface for joint movement and distributes the forces that occur within the musculoskeletal system to the underlying subchondral bone. AC lesions are a common clinical problem because they do not heal spontaneously and often progress to higher grade $\mathrm{AC}$ lesions and, over time, to osteoarthritis (OA) [1]. Consequently, higher grade $\mathrm{AC}$ lesions are the target of many clinical therapies and basic science studies that aim to restore the AC layer with tissue engineered implants or induced hyaline-like AC. The use of autologous chondrocytes from non-weight bearing regions of $\mathrm{AC}$ that are seeded into a scaffold for implantation is one such method, termed autologous chondrocyte implantation (ACI). ACI is a clinically successful therapy for $\mathrm{AC}$ [2] and osteochondral lesions $[3,4]$. However, as large-scale, degenerative AC and osteochondral lesions are a major focus of our field [5], the improvement of currently used ACI techniques and materials and the assessment of novel cell sources will gain more importance.

A crucial step in generating implants for ACI is the expansion of primary chondrocytes in monolayer culture to increase the number of available chondrocytes that are seeded into an implantable scaffold. Chondrocyte dedifferentiation in extended monolayer expansion [6] limits the time of monolayer expansion, and, thus, the amount of chondrocytes that can be generated for ACI. In this context, alternative cell sources that could be used instead or in combination with autologous chondrocytes from classically used biopsy sites such as the intercondylar notch are highly interesting. Other studies focused on lesion chondrocytes [7], OA-chondrocytes [8-10], and on progenitor cells [11], as these can be differentiated in vitro into desired lineages [12-14]. Potentially, an attractive source for autologous chondrocytes for knee ACI could be the osteochondral fragment that dislocates from an osteochondritis dissecans (OCD) lesion, as an older study reported that a large OCD defect of the weight-bearing knee joint surface was treated by transplantation of an autogeneic osteochondral fragment [15]. In this context, we have previously demonstrated that human chondrocytes isolated from OCD fragments are viable [16] and, compared to notch chondrocytes from the same human joints, have an comparable mRNA expression of AC tissue engineering-relevant types I and II collagen [17]. Also, the ratio of type I to II collagen, which presents the balance between a chondrogenic vs. a de-differentiated phenotype, was comparable between OCD fragment and notch chondrocytes, indicating a chondrogenic phenotype in both OCD fragment and notch chondrocytes [17]. However, monolayer expansion, which represents an important step for producing the cell numbers needed for generating ACI implants, changed the mRNA expression profiles of clinically used notch chondrocytes but also of OCD fragment chondrocytes towards a de-differentiated phenotype [17].

In the present study, we asked the question whether human OCD fragment-derived chondrocytes, after they were intentionally de-differentiated through monolayerexpansion, can be re-differentiated using the alginate bead system [18] as a three-dimensional (3D) ACI model. Thus, we investigated ex vivo chondrocyte yield, viability, morphology, and the aggrecan and types I, II, and $\mathrm{X}$ collagen mRNA expression profiles of human OCD fragment-derived chondrocytes. We compared these ex vivo characteristics with those after monolayer expansion, after primary alginate bead culture, and after alginate bead culture following monolayer expansion. Collectively, such information is relevant for using human OCD fragment-derived chondrocytes for clinical ACI but, unfortunately, this information has been unavailable until now.

\section{Methods \\ Articular cartilage}

AC grade 4 according to the International Cartilage Repair Society (ICRS) classification system [19] from the dissected OCD fragments of the knee joints of 15 OCD patients was used (Fig. 1). The associated demographic data of these patients are shown in Table 1. Routine MRI was used to confirm OCD diagnosis and general recommendations on inclusion and exclusion criteria were respected $[2,20]$. During the initial knee arthroscopy for generating $\mathrm{AC}$ biopsies for $\mathrm{ACI}$, OCD-fragments were harvested (Fig. 1) and transferred in standard medium to our research laboratory for further analyses. As routine surgical therapy, the OCD-affected bone was restored if necessary and matrix-associated ACI was used as previously described [21] using Novocart ${ }^{\oplus}$ 3D (TETEC, Reutlingen, Germany).

\section{Cell isolation and culture}

Chondrocytes were isolated from the biopsy material designated to this study by sequential protease digestion for $1 \mathrm{~h}$ in $0.2 \%$ pronase, followed by overnight digestion in $0.025 \%$ collagenase-P in DMEM / F-12 medium (GIBCO BRL; Life Technologies, Grand Island, New York), supplemented with $5 \%$ autologous serum and $50 \mu$ g gentamicin / ml. The released cells were counted manually and cell viability was assayed by Trypan blue exclusion. The chondrocytes were washed three times in phosphate-buffered saline (PBS). An aliquot of 10,000 cells was dissolved in RNA extraction buffer (TRIzol Reagent; Life Technologies, Gaithersburg, Maryland) for molecular analysis (analysis 1 ex vivo). Other isolated chondrocytes were cultured in alginate beads (see below) for 3 weeks, followed by successive analysis (analysis 2 


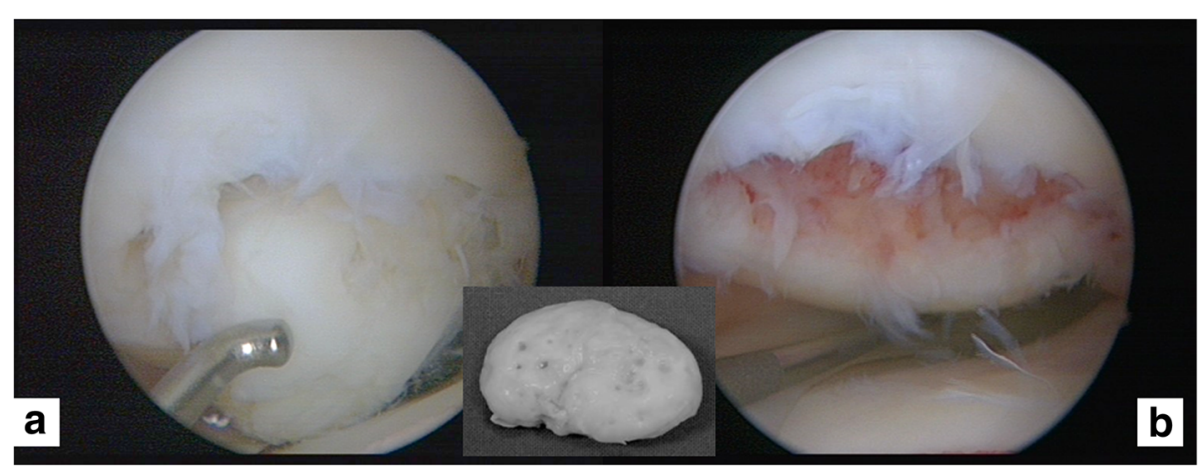

Fig. 1 Arthroscopic images of an osteochondritis dissecans (OCD) lesion ICRS grade 4 of the medial femoral condyle in a 24 year old male patient. a Gives the initial finding at arthroscopy. $\mathbf{b}$ Illustrates the lesion after debridement and the insert shows a representative image of an dislocated and arthroscopically removed OCD fragment

alginate). The remaining isolated chondrocytes that were not used for alginate culture were seeded in low-density monolayer culture for 3 weeks, comparable to the chondrocyte expansion routinely performed for ACI. This corresponded to approximately $2-3$ passages. The chondrocytes in alginate and monolayer were cultured at $37{ }^{\circ} \mathrm{C}$ and 5\% CO2 in standard DMEM / F12 feeding medium supplemented with $5 \%$ autologous serum and $50 \mu \mathrm{g}$ gentamicin. The medium was changed every other day. At the time of confluence the monolayer chondrocytes were liberated by trypsin digestion and washed three times in PBS. An aliquot of 10,000 chondrocytes was dissolved in RNA extraction buffer (TRIzol Reagent) for molecular analysis (analysis 3 monolayer). The remaining monolayer-expanded chondrocytes were cultured in alginate beads (see below) for another 3 weeks followed by subsequent analyses (analysis 4 monolayer \& alginate).

\section{Preparation and culture of alginate beads}

The isolated chondrocytes were encapsulated in alginate beads at a density of $4 \times 10^{6}$ cells / $\mathrm{ml}$ of alginate gel, as described by [22] modified by [18]. Briefly, the cells were suspended in sterile $0.15 \mathrm{M} \mathrm{NaCl}$ containing low-viscosity alginate gel (1.2\%), then slowly pressed through a 22 gauge needle in a dropwise fashion into a $102 \mathrm{mM} \mathrm{CaCl}_{2}$ solution. After instantaneous gelation the beads were allowed to polymerize further for a period of $10 \mathrm{~min}$ in the $\mathrm{CaCl}_{2}$ solution. After 1 wash in 10 volumes of $0.15 \mathrm{M} \mathrm{NaCl}$ and 3 washes in 10 volumes of Ham's F12 / DMEM medium,

Table 1 Details of the specimens used in this study

\begin{tabular}{ll}
\hline Number of knees & 15 \\
Mean age (years) (range) & $28(16-49)$ \\
Male: female & $10: 5$ \\
Site of OCD & 11 medial, 4 lateral \\
Mean defect size $\left(\mathrm{cm}^{2}\right)$ (range) & $4.6(3-8)$ \\
\hline
\end{tabular}

the beads were finally placed in standard culture medium (Ham's F-12 / DMEM medium (50 / 50) with 10\% FBS, $50 \mathrm{mg} / \mathrm{ml}$ gentamicin and $25 \mathrm{mg} / \mathrm{ml}$ ascorbic acid). Each bead contained an average chondrocyte number of $44 \pm 2 \times 10^{3}$ cells / bead. Nine beads were cultured per well of a 24-well plate. The cells were incubated at all stages in a humidified atmosphere of $5 \% \mathrm{CO}_{2}$ at $37^{\circ} \mathrm{C}$ and maintained by medium change 3 times per week with 1 . $5 \mathrm{ml}$ medium/well. After 3 weeks, the beads were dissolved with $1 \mathrm{ml}$ of $55 \mathrm{mM}$ sodium citrate, $0.15 \mathrm{M} \mathrm{NaCl}$, $\mathrm{pH} 6.05$, at $25{ }^{\circ} \mathrm{C}$ for $20 \mathrm{~min}$ and the chondrocytes were recovered by centrifugation [18].

Quantitative real-time polymerase chain reaction (qRT-PCR) Chondrocytes were dissolved in RNA extraction buffer ( $1 \mathrm{ml}$ TRIzol Reagent), and Chloroform $(200 \mu \mathrm{l})$ was added. After shaking and incubation for $3 \mathrm{~min}$ at room temperature, the samples were centrifuged for $15 \mathrm{~min}$ at $12000 \mathrm{~g}\left(4^{\circ} \mathrm{C}\right)$ for phase separation. Total RNA was then precipitated from the aqueous phase with isopropyl alcohol ( $0.5 \mathrm{ml}, 10 \mathrm{~min}$, room temperature), and centrifuged for $10 \mathrm{~min}$ at $12000 \mathrm{~g}$ and $4{ }^{\circ} \mathrm{C}$. Subsequently, the RNA was washed twice with $700 \mu \mathrm{l}$ of $75 \%$ ethanol, dried at $42{ }^{\circ} \mathrm{C}$, and re-dissolved in nuclease-free water, followed by digestion of genomic DNA using RNase free DNase (Qiagen, Hilden, Germany). Total RNA yield was assessed by spectrophotometry at $260 \mathrm{~nm}$. The cDNA was synthesized from $1 \mu \mathrm{g}$ of total RNA using the Omniscript RT Kit (Qiagen, Hilden, Germany) according to the manufacturer's protocol. Quantitative real-time PCR was performed in an iCycler iQ (Bio-Rad Laboratories, Hercules, California) in $20 \mu \mathrm{l}$ reaction volume containing 9.4 $\mu \mathrm{l} \mathrm{cDNA}, 0.3 \mu \mathrm{l}$ forward primer, $0.3 \mu \mathrm{l}$ reverse primer and $10 \mu \mathrm{l}$ iQ SYBR Green supermix (BioRad Laboratories). All investigated target genes and the sequences of their corresponding primers are listed in Table 2 . The primers were validated by gel analysis, are listed in the NCBI reference sequence database and have 
Table 2 Primers used for the polymerase chain reaction (PCR); F: forward primer sequence, R: reverse primer sequence

\begin{tabular}{lll}
\hline Gene Name & PubMed Accession Number & Sequence \\
\hline GAPDH & BT006893 & F: CAT CAC TGC CAC CCA GAA GA \\
Type X collagen & X98568 CCT GCT TCA CCA CCT TCT TG \\
$\begin{array}{ll}\text { Type I collagen } \\
\text { (COL1A2) }\end{array}$ & F: CCT CTT GTT AGT GCC AAC CAG \\
& XM_029245 & F: CTC TGC GAC ACA AGG AGT CT \\
$\begin{array}{l}\text { Type II collagen } \\
\text { (COL2A1) }\end{array}$ & R: ATC TTC ACC AGC CTT GCC AG \\
& X16711 CAA CAC TGC CAA CGT CCA GAT \\
Aggrecan & & R: CTG CTT CGT CCA GAT AGG CAA T \\
& NM_013227 & R: TCT TCC GCT GGT CAG ATG GA AGA TCA TCA CC \\
\hline
\end{tabular}

been used in our previous studies [16, 17, 23]. The sequence specificity was confirmed by BLAST searches. The reactions were run with appropriate controls (no template) to assess cross-contamination. The cycling parameters were: $95{ }^{\circ} \mathrm{C}$ for $3 \mathrm{~min} ; 40$ cycles: $94{ }^{\circ} \mathrm{C}$ for $20 \mathrm{~s}$, annealing at $60{ }^{\circ} \mathrm{C}$ for $20 \mathrm{~s}$, extension at $72{ }^{\circ} \mathrm{C}$ for $20 \mathrm{~s}$; and $95{ }^{\circ} \mathrm{C}$ for $1 \mathrm{~min}$. The PCR was evaluated by melting curve analysis. Data were calculated by the cycle threshold method (expressed as $2^{-\Delta C t}$ ), normalized to glyceraldehyde phosphate dehydrogenase (GAPDH) mRNA expression, and are presented as ratios. Amplification efficiencies and GAPDH stable expression as reference gene were confirmed for our previous studies [16, 17, 23], in which the same protocol was used.

\section{Histology}

A representative AC sample was fixed in 4\% paraformaldehyde and embedded in paraffin. Paraffin sections of $5 \mu \mathrm{m}$ thickness were prepared. Conventional staining included a routine dual stain with hematoxylin / eosin for cellular distribution and safranin-O / fast green for proteoglycan content. Alkaline phosphatase detection was performed using a commercially available kit according to the manufacturer's protocol (Pierce). Immunohistochemistry was performed with a mouse monoclonal antibody against human type I collagen (Oncogene Research Products, Boston, Massachusetts) and a rabbit polyclonal antibody against human type II collagen (Abcam, Cambridge, $\mathrm{UK}$ ) and type $\mathrm{X}$ collagen (kindly provided by Klaus von der Mark, University of Erlangen, Germany), as described earlier in our and other studies [16, 24].

\section{Statistical analyses}

Analyses were performed using SigmaPlot 11.0 and SigmaStat 3.0 (SPSS Inc., Chicago, USA). Analysis of variance (ANOVA) and normality testing were performed for all groups. Differences between the groups before or after cell culture were assessed with the Kruskal-Wallis one-way ANOVA on ranks. If the ANOVA tests for comparing chondrocytes before vs. after cell culture were statistically significant, an all-pairwise multiple comparison procedure (Student-Newman-Keuls Test) was performed to isolate the group or groups that differed from the others. Correlations were tested for significance by the Spearman's rank order correlation test. A $p<0.05$ was considered statistically significant.

\section{Results}

\section{Histology and immunohistochemistry}

The histological characteristics of a representative OCD AC fragment derived from the medial femoral condyle are shown in Fig. 2. Two overviews at $5 \times$ magnification depict the irregular superficial zone stained with hematoxylin and eosin and with safranin- $\mathrm{O}$ and fast green (Fig. 2a,b), illustrating a homogenous chondrocyte distribution throughout the extracellular matrix. The safranin-O and fast green stain (Fig. 2b) revealed that the central part of the fragment contained proteoglycans, whereas the superficial zone was depleted. Interestingly, there was an increased pericellular staining in the deep zone, indicating in increased proteoglycan deposition I in that zone (insert in B). Note the presence of a fibrous-appearing layer covering the superficial zone (Fig. 2a insert), whose immunostaining for type I and II collagen is depicted in Fig. 2c,d, revealing that type I collagen was present within the superficial zone and the fibrous layer and that collagen type II was present throughout the tissue. The phase contrast pictures (inserts in C and D) depict the entire section. Interestingly, alkaline phosphatase was detected throughout the tissue (Fig. 2e) in the pericellular area (insert in E), which was also true for type X collagen (Fig. 2f). Collectively, these images demonstrated that the examined OCD fragment contained the types I, II, and X collagen. 


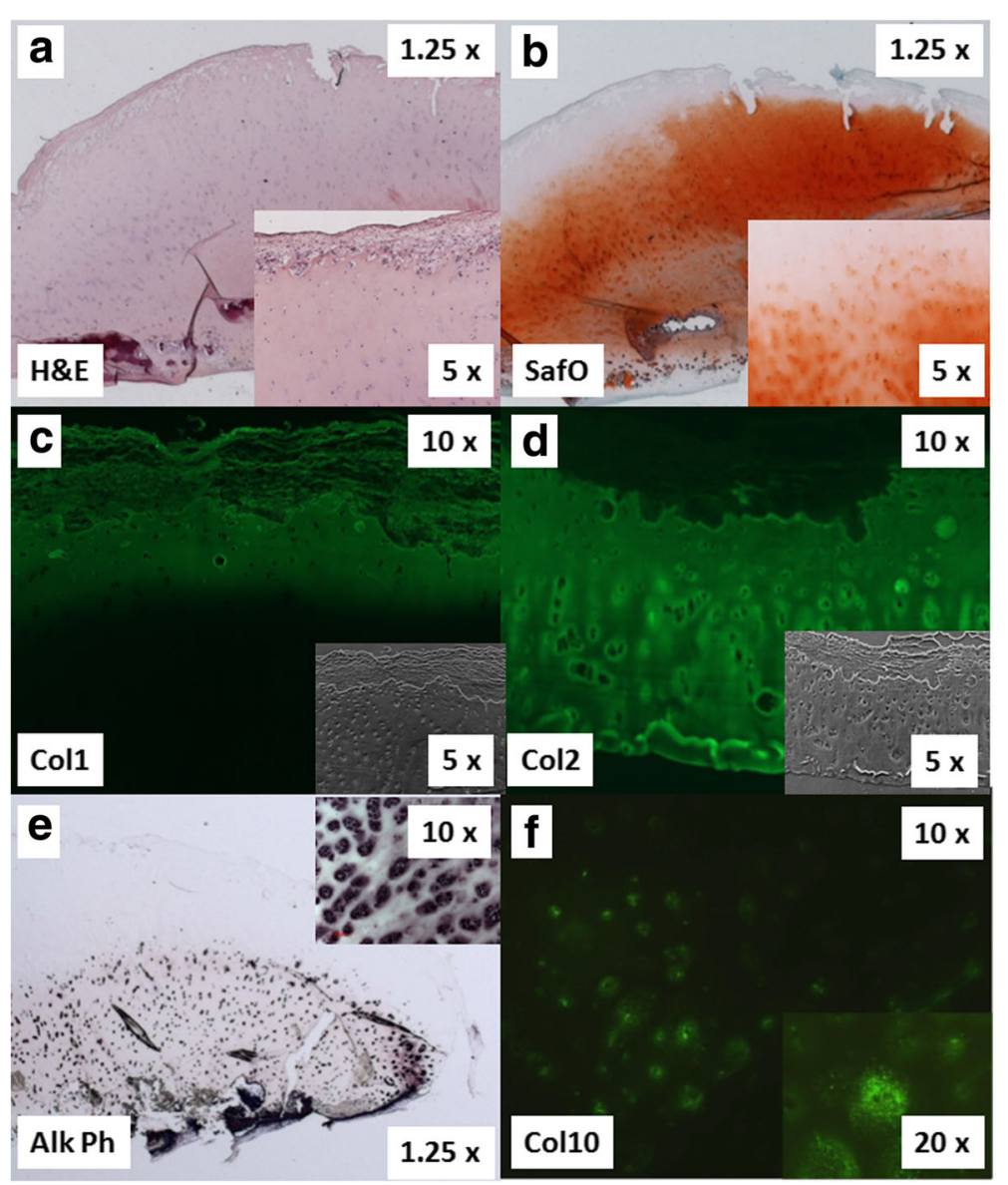

Fig. 2 Histology of a representative OCD fragment from the debrided ICRS grade 4 lesion of the medial condyle of a 22 year old patient. a Depicts a hematoxylin / eosin stain and (b) a safranin-O / fast green stain. c, d Shows immunostaining for types I (c) and II collagen (d) together with phase contrast images as inserts. e Shows alkaline phosphatase staining. $\mathbf{f}$ Shows immunostaining for type $X$ collagen. Original magnifications of $1.25 \times(\mathbf{a}, \mathbf{b}), 10 \times(\mathbf{c}-\mathbf{f})$ and insert magnifications of $5 \times(\mathbf{a}-\mathbf{d}), 10 \times(\mathbf{e}, \mathbf{f})$

\section{Chondrocyte yield, viability, and morphology}

Approximately $0.73 \pm 0.33 \times 10^{6}$ chondrocytes per gram wet weight were extracted. The mean cell viability was in all groups above $88 \%$ and no significant differences between the groups were noted. After isolation the suspended chondrocytes depicted a round phenotype but once seeded onto a tissue culture plate in low density the morphology had changed as expected to a more irregular and fibroblastic-appearing phenotype. After 3 weeks of monolayer expansion, the chondrocytes had regained this phenotype. During subsequent cultivation in alginate beads for another 3 weeks, the chondrocytes had changed to a round morphology. The number of isolated cells per OCD fragment and the viability of the individual cell cultures that were derived from these fragments is given in Table 3.

\section{Molecular analyses}

Molecular analyses revealed patient-specific mRNA expression variation on the order of magnitudes. Aggrecan mRNA expression (Fig. 3A) was comparable immediately after cell isolation (analysis 1) and after primary culture in alginate beads (analysis 2), which increased the expression 1.08 -fold but without any significant difference between the two groups. After expansion in monolayer culture (analysis 3), aggrecan mRNA expression was decreased to 0.007 -fold, compared to cell isolation and to alginate bead culture, and the difference was significant $(p<0.001)$, compared to both groups. After alginate bead culture following monolayer expansion (analysis 4), aggrecan mRNA expression was significantly increased 10.2 -fold $(p<0.001)$ , compared to monolayer expansion only (analysis 3 ). However, the expression levels were significantly lower than after isolation $(0.07$-fold, $p<0.001)$ or $3 \mathrm{D}$ culture I (0.07-fold, $p<0.001)$. Additional information on mRNA expression and cell viavility can be found in the supplementary file (Additional file 1).

Type I collagen mRNA expression (Fig. 3B) was increased after monolayer culture expansion (analysis 3), compared to ex vivo (analysis 1, 24.1-fold) and to alginate bead culture (analysis 2, 24.8-fold), and the difference was significant 
Table 3 Number of isolated cells per OCD fragment and viability of the individual cell cultures that were derived from these fragments

\begin{tabular}{|c|c|c|c|c|c|}
\hline \multirow{2}{*}{$\begin{array}{l}\text { OCD } \\
\text { Fragment }\end{array}$} & \multirow{2}{*}{$\begin{array}{l}\text { Cell } \\
\text { number } \\
(\times 100.000 / g \\
\text { wet weight })\end{array}$} & \multicolumn{4}{|c|}{ Viability after Cell Culture (\% of total) } \\
\hline & & Analysis 1 & Analysis 2 & Analysis 3 & Analysis 4 \\
\hline 1 & 0.72 & 91 & 89 & 93 & 92 \\
\hline 2 & 0.36 & 86 & 88 & 87 & 89 \\
\hline 3 & 0.8 & 75 & 79 & 81 & 85 \\
\hline 4 & 0.56 & 96 & 95 & 94 & 91 \\
\hline 5 & 1.24 & 90 & 96 & 90 & 93 \\
\hline 6 & 0.42 & 89 & 85 & 93 & 89 \\
\hline 7 & 1.01 & 93 & 93 & 85 & 89 \\
\hline 8 & 0.77 & 82 & 91 & 87 & 85 \\
\hline 9 & 0.9 & 87 & 85 & 89 & 96 \\
\hline 10 & 0.61 & 93 & 87 & 94 & 95 \\
\hline 11 & 1.23 & 95 & 94 & 92 & 93 \\
\hline 12 & 0.31 & 96 & 97 & 95 & 91 \\
\hline 13 & 0.37 & 87 & 92 & 89 & 84 \\
\hline 14 & 0.41 & 91 & 93 & 92 & 90 \\
\hline 15 & 1.22 & 92 & 93 & 90 & 92 \\
\hline
\end{tabular}

$(p<0.001)$, compared to both groups. After alginate bead culture following monolayer expansion (analysis 4), type I collagen mRNA expression was significantly decreased to 0.5 -fold $(p<0.001)$, compared to monolayer expansion only (analysis 3 ). However, the expression levels were significantly higher than ex vivo (analysis 1, 12.5fold, $p<0.001$ ) or after alginate bead culture (analysis 2, 12.9-fold, $p<0.001$ ).

Type II collagen mRNA expression (Fig. 3C) was not significantly different after primary culture in alginate beads (analysis 2) vs. ex vivo (analysis 1). After expansion in monolayer culture (analysis 3 ), type II collagen mRNA expression was decreased to 0.003-fold, compared to ex vivo (analysis 1 ) and 0.004-fold compared to alginate bead culture (analysis 2). The difference was significant $(p<0$. 001), compared to both groups. After alginate bead culture following monolayer expansion (analysis 4), type II collagen mRNA expression was significantly increased to 4.5 -fold $(p<0.001)$, compared to monolayer expansion (analysis 3). However, the expression levels were significantly lower than ex vivo (analysis 1, 0.012-fold, $p<0.001$ ) or alginate bead culture (analysis 2, 0.019-fold, $p<0.001$ ).

Type X collagen mRNA expression (Fig. 3D) was not significantly changed after alginate bead culture (analysis 2 ), compared to ex vivo (analysis 1). After monolayer expansion (analysis 3), the type collagen X mRNA expression was significantly decreased to 0.03 -fold, compared to ex vivo (analysis $1, p<0.001$ ). It further decreased after alginate bead culture following monolayer expansion (analysis $4, p<0.001$ ) by 0.6 -fold, compared to monolayer expansion (analysis 3), or decreased 0.01-fold, compared to ex vivo (analysis 1 ).

The ratio of type I to II collagen mRNA expression (Fig. 3E), which we calculated for each OCD fragment from the types I and II collagen mRNA expression values, was comparable ex vivo (analysis 1, $0.026 \pm 0$. 035 ) and after alginate bead culture (analysis 2, $0.054 \pm$ 0.09 , 3D culture I), as the trend towards a 0.49 -fold decrease after alginate bead culture did not reach significance. For both groups the ratio values were $<1$, indicating a higher type II than I collagen mRNA expression and, thus, a healthy chondrocyte function. After monolayer expansion (analysis 3), the ratio was increased to $69.61 \pm 47.7$ and the increase was significant, compared to both groups $(p<0.001)$. After alginate bead culture following monolayer expansion (analysis 4), the ratio value was $7.23 \pm 4.2$, which indicated a significant recovery of the ratio, compared to monolayer expansion (analysis 3, $p<001$, Fig. 3).

We also analyzed the data to uncover potential differences between medial and lateral defect locations. However, the mRNA expression data obtained from analyses 1 to 4 for chondrocytes from the medial vs. lateral defect locations were not significantly different (except type I collagen expression in the group analysis 2).

\section{Correlation analyses}

Ex vivo aggrecan mRNA expression levels (analysis 1) correlated significantly and positively with those after culture in alginate beads (analysis $2, p<0.001$, correlation coefficient cc: 0.988). Moreover, the ex vivo mRNA expression of collagen type I (analysis 1) correlated significantly and positively with the expression levels in primary alginate bead culture (analyses 2, $p=0.005$, cc: 0.682 ). The same was true for the collagen types II $(p<0.001$, cc: 0.989$)$ and $\mathrm{X}(p<0.001$, cc: 0.986$)$ expression levels, indicating that a high ex vivo expression of aggrecan, collagen types I, II, and $\mathrm{X}$ were associated with a high expression in primary alginate culture.

Interestingly, the mRNA expression levels after monolayer expansion (analysis 3) of all genes of interest correlated significantly and positively with the expression levels after alginate bead culture following monolayer expansion (analysis 4; aggrecan: $p<0.001$, cc: 0.913 ; collagen type I: $p<0.001$, cc: 0.973 ; collagen type II: $p<0.001$, cc: 0.987 ; collagen type $\mathrm{x}: p<0.001, \mathrm{cc}: 0.981)$. This indicated that OCD fragment-derived chondrocytes with a relatively high mRNA expression of these genes in monolayer culture had also high expression levels in subsequent alginate bead culture following monolayer expansion. Together, these data indicated that patient-specific mRNA 

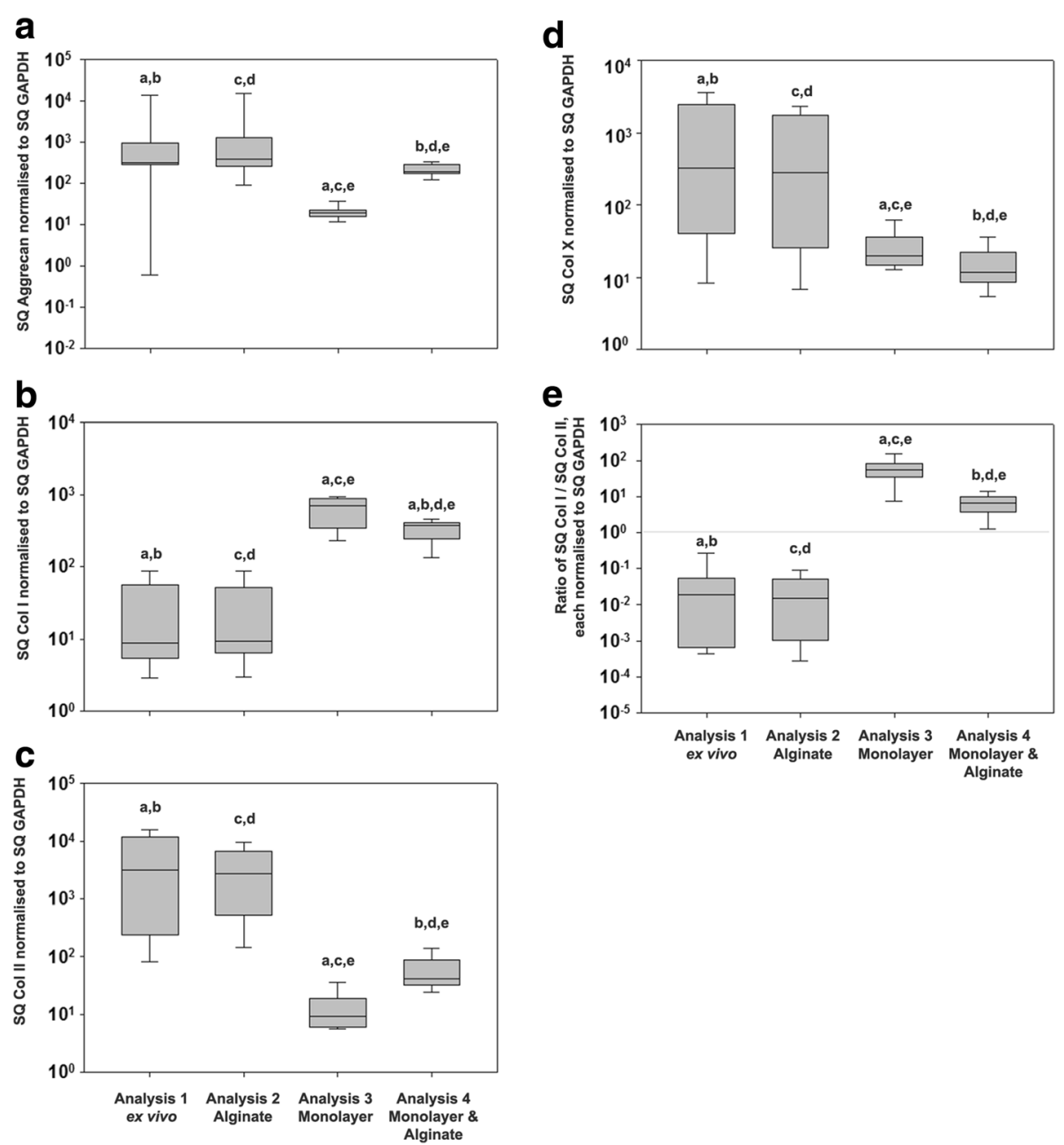

Fig. 3 Comparison of OCD fragment-derived chondrocyte mRNA expression ex vivo, after alginate bead culture, after monolayer culture, and after monolayer culture followed by successive alginate bead culture. This figure depicts the mRNA expression of aggrecan (a), types I (b), II (c), and X collagen (d) of OCD fragment-derived chondrocytes. (e) gives the ratio of type I to II collagen mRNA expression, which illustrates the balance between a functional chondrocyte phenotype (value $<1$ ) as in intact cartilage and a de-differentiated in vitro phenotype (value $>1$ ). The transition between both phenotypes is indicated by a grey line. Data are shown as box plots with each box representing the 25th and 75th percentile and the whiskers the 10th and 90th percentiles. Solid lines within the box indicate the median. Significant differences of pairwise comparisons are indicated by small letters. E.g. "a" indicates that the comparison of the type I collagen mRNA expression in (b) between analysis 1 (ex vivo) and analysis 3 (monolayer) was significant

expression level variations were maintained across the culture systems used.

\section{Discussion}

The present study asked whether intentionally in monolayer de-differentiated human OCD fragment-derived chondrocytes can be re-differentiated by using the alginate bead system [18] as an in vitro 3D ACI model. First, we demonstrated that chondrocytes can be isolated from the dissected OCD fragments of human patients with a sufficient yield and viability that was consistent with the literature [16]. Furthermore, ex vivo OCD fragmentderived chondrocytes displayed a functional chondrocyte phenotype, which was determined by calculating the ratio of type I to II collagen mRNA expression. The ratio was comparable to those of chondrocytes from the notch and from $\mathrm{AC}$ lesions of human knee joints [7], suggesting a comparable chondrogenic phenotype of cells from these three AC locations. As expected, monolayer expansion led to chondrocyte de-differentiation [6], based on an irregular and fibroblastic-appearing phenotype and a decreased aggrecan and type II collagen mRNA expression and simultaneous increases in the type I collagen mRNA expression and the type I to II collagen expression ratio, compared to ex vivo. Subsequent alginate bead culture of the monolayer-expanded, de-differentiated OCD fragmentderived chondrocytes led to changes in cell morphology and mRNA expression that were consistent with re- 
differentiating the de-differentiated OCD fragment-derived chondrocytes. However, although we noted increased aggrecan and type II collagen mRNA expression levels and decreases in the type I collagen mRNA expression and the type I to II collagen expression ratio, the resulting mRNA expression values were significantly different from those measured ex vivo. Thus, induced re-differentiation was only partially successful in recovering the mRNA expression profiles. Interestingly, the type $\mathrm{X}$ collagen mRNA expression of OCD fragment-derived chondrocytes was lowest after re-differentiation of monolayer-induced dedifferentiation in alginate beads, compared to primary alginate bead culture, monolayer expansion, and even compared to ex vivo. That monolayer expansion led to a significant reduction in the type X collagen mRNA expression or, as an alternative explanation, to the selection of a less hypertrophic cell pool was consistent with our previous study [17]. Collectively, this study demonstrated that ex vivo OCD fragment-derived chondrocytes were characterized by a chondrogenic but also hypertrophic phenotype, based on the low type I to II collagen expression ratio, and at the same time the high type X collagen mRNA expression. After monolayer expansion, the re-differentiation through alginate bead culture was most effective in modulating the mRNA expression of type $\mathrm{X}$ collagen and, to a lesser extent, of aggrecan but was not effective in lowering the collagen type I to II expression ratio to values below 1 . Thus, induced re-differentiation led to a marked reduction of the hypertrophic phenotype to approximately $1.5 \%$ of its ex vivo value but did not fully restore the chondrogenic phenotype, measured as type I to II collagen expression ratio. Collectively, OCD fragment-derived cells are interesting chondrogenic but also hypertrophic chondrocytes, whose re-differentiation with the here described method was effective in modulating hypertrophic but not chondrogenic characteristics. Subsequent procedures for improving the chondrogenic properties of OCD-fragment-derived cells would greatly enhance their clinical potential.

For inducing chondrocyte re-differentiation, previous studies have used alginate bead and pellet culture [25], alginate bead culture combined with serum or growth factor cocktails [26], hypoxic pellet culture [27], porous scaffold surfaces for the co-culture with mesenchymal stromal cells [28], agarose [29] and photocrosslinkable hydrogels [30], as well as the chimeric Activin A / BMP2 ligand AB235 [31]. These studies investigated the redifferentiation of human OA-chondrocytes obtained during joint replacement procedures [25-27, 30, 31] and of porcine and bovine chondrocytes [28, 29]. As human chondrocytes derived from dislocated OCD fragments have not been investigated, the present study added an important part to the literature on chondrocyte redifferentiation. Re-differentiation in 3D can be enhanced by adding human serum or transforming growth factor beta1 and insulin-transferrin-selenium-linoleic acidbovine serum albumin [26] or human mesenchymal stromal cells [28], by using hypoxic conditions [27], by varying adhesion site density but not stiffness [29], and by choosing re-differentiation-supporting biomaterials such as hyaluronic acid hydrogels [30]. In the present study, the re-differentiation-associated changes in mRNA expression were comparable to [25], in which changes in mRNA expression were induced via $3 \mathrm{D}$ alginate bead cultures after chondrocyte de-differentiation. In line with our study, [25] reported a significantly decreased type X collagen mRNA expression and increased types I and II collagen and aggrecan expression. In this respect, the effects of alginate bead culture for re-differentiating OCD fragment-derived chondrocytes appeared comparable to human OA-chondrocytes obtained during joint replacement procedures.

A recent study investigated the frequency of OCD fragment chondrocyte cultures and reported that it was possible to culture chondrocytes from traumatic osteochondral fragments within a year of injury but not from fragments due to OCD [32]. This interesting study suggested that the time elapsed between loose body formation and fragment excision was the main factor affecting the cell culture setup. Our data does not allow drawing a direct comparison, as we did not record the time between loose body formation and cell isolation. However, we noted two methodological differences between the studies. Whereas [32] used enzymatic digestion with collagenase-A overnight, the present study used a sequential digestion for $1 \mathrm{~h}$ in pronase, followed by overnight digestion in collagenase-P. Another independent study [33] used the same sequential digestion used here and reported a comparably high viability in each studied OCD fragment but did not attempt cell culture. Additionally, the culture conditions between [32] and our study differed, as [32] used $10 \%$ of fetal bovine serum and the present study used 5\% autologous serum. Together, these methodological differences may explain in part the difference in the number of successfully established OCD fragment-derived chondrocyte cultures. Thus, a head-tohead comparison of these different methods together with information on time since disease onset as suggested by [32] may help to determine the optimal conditions and the expected frequency of successfully established OCD fragment-derived chondrocytes.

It is worthwhile to mention that recent research on healthy (porcine) AC identified GAPDH as one of the most stably expressed genes [34], whereas it is considered a less stable reference gene in full osteoarthritis (human) patients older than 60 years [35]. As the choice of the appropriate reference gene depends on the individual experimental set-up [36], we had confirmed the suitability of the chosen reference gene for our previous studies. However, the method could be improved upon because MIQE guidelines encourage using more than one 
reference gene [37]. Generally, the methodology of the present study was chosen to allow better comparisons to our previous studies [16, 17, 23, 38]. A previous study comparing the here chosen method of SYBR Green based detection to TaqMan based detection found TaqMan to be more sensitive and to generate lower calculated expression levels than the SYBR Green assay, suggesting that any discussion of gene expression levels needs to be linked to the qPCR method used in the analysis [39]. However, this was not of great concern in the present study because our main conclusions were based on the expression ratio of type I to II collagen as well as relative changes in aggrecan and types II and X collagen mRNA expression. Also in a methods context, it is worth mentioning that dedifferentiation of monolayer cultured chondrocytes is a progressive process that depends on passage and culture time $[26,40]$. Thus, one can chose either time or passage number for culture standardization. Here, we chose a standardized culture time of 3 weeks, according to [26], which corresponded to approximately $2-3$ passages. We did not analyze the re-differentiation status as a function of chondrocyte passage number, although this would be interesting data.

Although we calculated the number of isolated cells per OCD fragment wet weight, we did not record the total number of cells that were contained within the fragment at the time of isolation because we allocated the cell suspension into 4 cell culture groups. Thus, we cannot directly assess whether all OCD fragments would have qualified for ACI, based on cell numbers. However, the sparse literature on this topic documents that a range of cell densities is being used for ACI [41]. Additionally, in the personal experience of the authors OCD fragments can be processed for later $\mathrm{ACI}$ as a future therapy option, regardless of the initial cell number.

As the cell quality affects the clinical outcome of ACI [42], it is helpful to mention that OCD fragment-derived chondrocyte exhibited a patient-specific variation of the mRNA expression that was on the order of magnitudes. Specifically, the chondrocytes from certain donors had a more chondrogenic mRNA expression profile than the cells from other donors. These variations were not associated with any patient demographics. However, we noted through our correlation analyses that the patient-specific variations in the mRNA expression levels were maintained across the culture systems used. This indicated that patient-specific expression characteristics measured ex vivo were maintained in vitro throughout de-differentiation and induced re-differentiation. Whether such patient-specific expression characteristics can potentially be preserved after implantation is not known. In the context of cell quality, it appears also important to choose an appropriate cell source for ACI. Studies that examine joint locations are valuable, as chondrocytes from diverse locations differ in many characteristics. For example, their metabolic characteristics vary across joints [10, 43]. Moreover, the cellular distribution within the native tissue varies between individual joints [44] and even joint surfaces within the same joint [44, 45] and between different stages of OA [46]. In clinical routine, ACI utilizes biopsies of macroscopically intact cartilage from non-weight bearing areas of the (knee) joint [47] such as the intercondylar notch and the trochlea. To determine the "best cell source" for regenerative cartilage therapies, one study investigated chondrocytes isolated from AC lesions vs. from healthy AC [48]. Interestingly, chondrocytes from the $\mathrm{AC}$ lesion performed better than from healthy $\mathrm{AC}$ and it was concluded that $\mathrm{AC}$ lesions could be viable donor sites for ACI. In this regard, chondrocytes from alternative cell sources such as AC lesions [48] may hold clinical potential for AC repair but need further investigation, as in the case of $\mathrm{AC}$ lesions - conflicting evidence has been reported [49]. However, in the case of knee OCD fragmentderived chondrocytes, the here reported biological characteristics are in accordance with our previous studies on this topic $[16,17]$ and clinical experience for OCD repair of the talus is promising [50]. Thus, we also analyzed the here reported data to uncover potential differences between medial and lateral defect locations. However, our data suggested that defect location did not have a significant effect on the ex vivo mRNA expression profile or the expression profiles after alginate culture, monolayer expansion, or alginate culture after monolayer expansion-induced dedifferentiation.

\section{Conclusion}

Collectively, human OCD fragment-derived chondrocytes depict chondrogenic but also hypertrophic characteristics, whose re-differentiation with the here described method was effective in modulating hypertrophic characteristics and to a lesser extent chondrogenic characteristics. The here presented data are important for better understanding and ultimately utilizing the clinical potential of human OCD fragment-derived chondrocytes for AC repair.

\section{Additional file}

Additional file 1: mRNA expression values for collagen types I, II, and X (Col I, Col II, and Col X, respectively) and aggrecan as well as cell viability. (DOC $40 \mathrm{~kb}$ )

\section{Acknowledgements}

We would like to thank Jana Schömburg und Christine Mollenhauer for their help in sample preparation and Dr. Juergen Mollenhauer for discussing this project. All data were collected at the Orthopaedic Research Laboratories of the University of Jena. We also thank the Deutsche Forschungsgemeinschaft (DFG), the Deutsche Arthrosehilfe e. V., and the Interdisciplinary Center for Clinical Research (IZKF) of the University of Jena for supporting this work. 


\section{Funding}

This work was supported in part by the Deutsche Forschungsgemeinschaft (DFG 156/6-1), the Deutsche Arthrosehilfe e. V., and the Interdisciplinary Center for Clinical Research (IZKF) (M.A.).

\section{Availability of data and materials}

The datasets concerning this study are available from the corresponding author on request.

\section{Authors' contributions}

$\mathrm{MA}, \mathrm{GOH}$, and BR conceived the study, participated in its design, and helped drafting the manuscript. All authors (MA, GOH, FG, BR) interpreted the data. MA, FG, and BR analyzed the data statistically. MA and BR were major contributors to writing the manuscript. All authors have read and approved the final manuscript. BR is the corresponding author.

\section{Ethics approval and consent to participate}

The study has been approved by the local ethics committee (approval \#0981-10 / 02) of the Ethics Committee of the Medical Faculty at the University of Jena, Jena, Germany) and was performed in accordance with the 1964 Declaration of Helsinki and the German Data Protection Act. Before starting this investigation, written informed consent was obtained. At any time, the patients had the right to withdraw consent without giving reasons and without disadvantages regarding further medical treatment. Any patient had the right to have his / her data deleted. The legal requirements concerning confidential medical communication were fully met. Patient data were stored exclusively in the Hospital according to current data protection laws. Third persons were not provided insight into source data. The medical therapy of the patients during hospitalization was performed independently of this research project.

\section{Competing interests}

The authors declare that they have no competing interests.

\section{Publisher's Note}

Springer Nature remains neutral with regard to jurisdictional claims in published maps and institutional affiliations.

\section{Author details}

${ }^{1}$ Center for Orthopaedic and Trauma Surgery, Klinikum Mittleres Erzgebirge, Alte Marienberger, Str. 52, 09405 Zschopau, Germany. ${ }^{2}$ Department of Trauma, Hand and Reconstructive Surgery, Universitätsklinikum Jena, Erlanger Allee 101, 07747 Jena, Germany. ${ }^{3}$ Department of Biochemistry, Rush Medical College, 1735 W. Harrison St, Chicago, IL 60612, USA. ${ }^{4}$ G.E.R.N. Tissue Replacement, Regeneration \& Neogenesis, Department of Orthopedics and Trauma Surgery, Medical Center - Albert-Ludwigs-University of Freiburg, Faculty of Medicine, Albert-Ludwigs-University of Freiburg, Hugstetter Straße 55, 79106 Freiburg, Germany. ${ }^{5}$ Massachusetts Institute of Technology, Center for Biomedical Engineering, 500 Technology Sq, Cambridge, MA 02139, USA.

\section{Received: 4 December 2017 Accepted: 7 May 2018}

\section{Published online: 24 May 2018}

\section{References}

1. Heijink A, Gomoll AH, Madry H, Drobnic M, Filardo G, Espregueira-Mendes J, Van Dijk CN. Biomechanical considerations in the pathogenesis of osteoarthritis of the knee. Knee Surg Sports Traumatol Arthrosc. 2012;20: 423-35. https://doi.org/10.1007/s00167-011-1818-0.

2. Niemeyer $P$, Albrecht $D$, Andereya $S$, Angele $P$, Ateschrang A, Aurich M, Baumann M, Bosch U, Erggelet C, Fickert S, Gebhard H, Gelse K, Gunther D, Hoburg A, Kasten P, Kolombe T, Madry H, Marlovits S, Meenen NM, Muller PE, Noth U, Petersen JP, Pietschmann M, Richter W, Rolauffs B, Rhunau K, Schewe B, Steinert A, Steinwachs MR, Welsch GH, Zinser W, Fritz J. Autologous chondrocyte implantation (ACl) for cartilage defects of the knee: a guideline by the working group "clinical tissue regeneration" of the German Society of Orthopaedics and Trauma (DGOU). Knee. 2016; https:// doi.org/10.1016/j.knee.2016.02.001.

3. Aurich M, Bedi HS, Smith PJ, Rolauffs B, Muckley T, Clayton J, Blackney M. Arthroscopic treatment of osteochondral lesions of the ankle with matrixassociated chondrocyte implantation: early clinical and magnetic resonance imaging results. Am J Sports Med. 2011;39:311-9. https://doi.org/10.1177/ 0363546510381575.

4. Ochs BG, Muller-Horvat C, Albrecht D, Schewe B, Weise K, Aicher WK, Rolauffs B. Remodeling of articular cartilage and subchondral bone after bone grafting and matrix-associated autologous chondrocyte implantation for osteochondritis dissecans of the knee. Am J Sports Med. 2011;39:764-73. https://doi.org/10.1177/0363546510388896.

5. Johnstone B, Alini M, Cucchiarini M, Dodge GR, Eglin D, Guilak F, Madry H, Mata A, Mauck RL, Semino CE, Stoddart MJ. Tissue engineering for articular cartilage repair-the state of the art. Eur Cells Mater. 2013;25:248-67.

6. Lin Z, Fitzgerald JB, Xu J, Willers C, Wood D, Grodzinsky AJ, Zheng MH. Gene expression profiles of human chondrocytes during passaged monolayer cultivation. J Orthop Res. 2008;26:1230-7. https://doi.org/10. 1002/jor.20523.

7. Aurich M, Hofmann GO, Best N, Rolauffs B. Induced Redifferentiation of human chondrocytes from articular cartilage lesion in alginate bead culture after monolayer dedifferentiation: an alternative cell source for cell-based therapies? Tissue Eng A. 2017; https://doi.org/10.1089/ten.TEA.2016.0505.

8. Stoop R, Albrecht D, Gaissmaier C, Fritz J, Felka T, Rudert M, Aicher WK Comparison of marker gene expression in chondrocytes from patients receiving autologous chondrocyte transplantation versus osteoarthritis patients. Arthritis Res Ther. 2007;9:R60. https://doi.org/10.1186/ar2218.

9. Cavallo C, Desando G, Facchini A, Grigolo B. Chondrocytes from patients with osteoarthritis express typical extracellular matrix molecules once grown onto a three-dimensional hyaluronan-based scaffold. J Biomed Mater Res A. 2010;93:86-95. https://doi.org/10.1002/jbm.a.32547.

10. Aurich M, Hofmann GO, Rolauffs B. Differences in type II collagen turnover of osteoarthritic human knee and ankle joints. Int Orthop. 2017:41:999-1005. https://doi.org/10.1007/s00264-017-3414-5.

11. Shafiee A, Kabiri M, Langroudi L, Soleimani M, Ai J. Evaluation and comparison of the in vitro characteristics and chondrogenic capacity of four adult stem/progenitor cells for cartilage cell-based repair. J Biomed Mater Res A. 2015; https://doi.org/10.1002/jbm.a.35603.

12. Bianco P, Cao X, Frenette PS, Mao JJ, Robey PG, Simmons PJ, Wang CY. The meaning, the sense and the significance: translating the science of mesenchymal stem cells into medicine. Nat Med. 2013;19:35-42. https://doi. org/10.1038/nm.3028.

13. Aicher WK, Buhring HJ, Hart M, Rolauffs B, Badke A, Klein G. Regeneration of cartilage and bone by defined subsets of mesenchymal stromal cellspotential and pitfalls. Adv Drug Deliv Rev. 2011;63:342-51. https://doi.org/ 10.1016/j.addr.2010.12.004.

14. Pilz GA, Ulrich $C$, Ruh M, Abele H, Schafer R, Kluba T, Buhring HJ, Rolauffs $B$, Aicher WK. Human term placenta-derived mesenchymal stromal cells are less prone to osteogenic differentiation than bone marrow-derived mesenchymal stromal cells. Stem Cells Dev. 2011;20:635-46. https://doi.org/ 10.1089/scd.2010.0308.

15. Yamashita F, Sakakida K, Suzu F, Takai S. The transplantation of an autogeneic osteochondral fragment for osteochondritis dissecans of the knee. Clin Orthop Relat Res. 1985:(201):43-50.

16. Aurich M, Anders J, Trommer T, Liesaus E, Seifert M, Schomburg J, Rolauffs B, Wagner A, Mollenhauer J. Histological and cell biological characterization of dissected cartilage fragments in human osteochondritis dissecans of the femoral condyle. Arch Orthop Trauma Surg. 2006;126:606-14. https://doi. org/10.1007/s00402-006-0125-6.

17. Aurich M, Hofmann GO, Muckley T, Mollenhauer J, Rolauffs B. In vitro phenotypic modulation of chondrocytes from knees of patients with osteochondritis dissecans: implications for chondrocyte implantation procedures. J Bone Joint Surg Br. 2012;94:62-7. https://doi.org/10.1302/ 0301-620X.94B1.27528.

18. Hauselmann HJ, Aydelotte MB, Schumacher BL, Kuettner KE, Gitelis SH, Thonar EJ. Synthesis and turnover of proteoglycans by human and bovine adult articular chondrocytes cultured in alginate beads. Matrix. 1992;12:116-29.

19. Brittberg M, Winalski CS. Evaluation of cartilage injuries and repair. J Bone Joint Surg Am. 2003;85-A(Suppl 2):58-69.

20. Niemeyer $P$, Andereya $S$, Angele $P$, Ateschrang A, Aurich M, Baumann M, Behrens P, Bosch U, Erggelet C, Fickert S, Fritz J, Gebhard H, Gelse K, Gunther D, Hoburg A, Kasten P, Kolombe T, Madry H, Marlovits S, Meenen NM, Muller PE, Noth U, Petersen JP, Pietschmann M, Richter W, Rolauffs B, Rhunau K, Schewe B, Steinert A, Steinwachs MR, Welsch GH, Zinser W, Albrecht D. Autologous chondrocyte implantation (ACI) for cartilage defects 
of the knee: a guideline by the working group "tissue regeneration" of the German Society of Orthopaedic Surgery and Traumatology (DGOU). Z Orthop Unfall. 2013;151:38-47. https://doi.org/10.1055/s-0032-1328207.

21. Marlovits S, Zeller P, Singer P, Resinger C, Vecsei V. Cartilage repair: generations of autologous chondrocyte transplantation. Eur J Radiol. 2006; 57:24-31. https://doi.org/10.1016/j.ejrad.2005.08.009.

22. Guo JF, Jourdian GW, MacCallum DK. Culture and growth characteristics of chondrocytes encapsulated in alginate beads. Connect Tissue Res. 1989;19: 277-97. https://doi.org/10.3109/03008208909043901.

23. Aurich $M$, Hofmann GO, Best N, Rolauffs B. Induced Redifferentiation of human chondrocytes from articular cartilage lesion in alginate bead culture after monolayer dedifferentiation: an alternative cell source for cell-based therapies? Tissue Eng A. 2018;24:275-86. https://doi.org/10. 1089/ten.TEA.2016.0505.

24. Correia C, Pereira AL, Duarte AR, Frias AM, Pedro AJ, Oliveira JT, Sousa RA, Reis RL. Dynamic culturing of cartilage tissue: the significance of hydrostatic pressure. Tissue Eng A. 2012;18:1979-91. https://doi.org/10 1089/ten.TEA.2012.0083.

25. Caron MM, Emans PJ, Coolsen MM, Voss L, Surtel DA, Cremers A, van Rhijn LW, Welting TJ. Redifferentiation of dedifferentiated human articular chondrocytes: comparison of 2D and 3D cultures. Osteoarthr Cartil. 2012;20: 1170-8. https://doi.org/10.1016/j.joca.2012.06.016.

26. Hsieh-Bonassera ND, Wu I, Lin JK, Schumacher BL, Chen AC, Masuda K, Bugbee WD, Sah RL. Expansion and redifferentiation of chondrocytes from osteoarthritic cartilage: cells for human cartilage tissue engineering. Tissue Eng A. 2009;15:3513-23. https://doi.org/10.1089/ten.TEA.2008.0628.

27. Babur BK, Ghanavi P, Levett P, Lott WB, Klein T, Cooper-White JJ, Crawford R, Doran MR. The interplay between chondrocyte redifferentiation pellet size and oxygen concentration. PLoS One. 2013;8:e58865. https://doi.org/10. 1371/journal.pone.0058865.

28. Meretoja W, Dahlin RL, Wright S, Kasper FK, Mikos AG. Articular chondrocyte redifferentiation in $3 \mathrm{D}$ co-cultures with mesenchymal stem cells. Tissue Eng Part C Methods. 2014;20:514-23. https://doi.org/10.1089/ten.tec.2013.0532.

29. Schuh E, Hofmann S, Stok K, Notbohm H, Muller R, Rotter N. Chondrocyte redifferentiation in 3D: the effect of adhesion site density and substrate elasticity. J Biomed Mater Res A. 2012;100:38-47. https:// doi.org/10.1002/jbm.a.33226.

30. Levett PA, Melchels FP, Schrobback K, Hutmacher DW, Malda J, Klein TJ. Chondrocyte redifferentiation and construct mechanical property development in single-component photocrosslinkable hydrogels. J Biomed Mater Res A. 2014;102:2544-53. https://doi.org/10.1002/jbm.a.34924.

31. Jimenez G, Lopez-Ruiz E, Kwiatkowski W, Montanez E, Arrebola F, Carrillo E, Gray PC, Izpisua Belmonte JC, Choe S, Peran M, Marchal JA. Activin a/BMP2 chimera AB235 drives efficient redifferentiation of long term cultured autologous chondrocytes. Sci Rep. 2015;5:16400. https:/ doi.org/10.1038/srep16400.

32. Guillen-Garcia P, Rodriguez-Inigo E, Guillen-Vicente I, Guillen-Vicente M, Fernandez-Jaen T, Concejero V, Val D, Maestro A, Abelow S, LopezAlcorocho JM. Viability of pathologic cartilage fragments as a source for autologous chondrocyte cultures. Cartilage. 2016;7:149-56. https://doi.org/ 10.1177/1947603515621998.

33. Pascual-Garrido C, Tanoira I, Muscolo DL, Ayerza MA, Makino A. Viability of loose body fragments in osteochondritis dissecans of the knee. A series of cases. Int Orthop. 2010;34:827-31. https://doi.org/10.1007/ s00264-010-0951-6.

34. McCulloch RS, Ashwell MS, O'Nan AT, Mente PL. Identification of stable normalization genes for quantitative real-time PCR in porcine articular cartilage. J Anim Sci Biotechnol. 2012;3:36. https://doi.org/10. 1186/2049-1891-3-36

35. Pombo-Suarez M, Calaza M, Gomez-Reino JJ, Gonzalez A. Reference genes for normalization of gene expression studies in human osteoarthritic articular cartilage. BMC Mol Biol. 2008;9:17. https://doi.org/ 10.1186/1471-2199-9-17

36. Al-Sabah A, Stadnik P, Gilbert SJ, Duance VC, Blain EJ. Importance of reference gene selection for articular cartilage mechanobiology studies. Osteoarthr Cartil. 2016;24:719-30. https://doi.org/10.1016/j.joca.2015.11.007.

37. Bustin SA, Benes V, Garson JA, Hellemans J, Huggett J, Kubista M, Mueller R, Nolan T, Pfaffl MW, Shipley GL, Vandesompele J, Wittwer CT. The MIQE guidelines: minimum information for publication of quantitative real-time PCR experiments. Clin Chem. 2009;55:611-22. https://doi.org/10.1373/ clinchem.2008.112797.
38. Aurich M, Hofmann GO, Rolauffs B. Tissue engineering-relevant characteristics of ex vivo and monolayer-expanded chondrocytes from the notch versus trochlea of human knee joints. Int Orthop. 2017;41:2327-35. https://doi.org/10.1007/s00264-017-3615-y.

39. Cao H, Shockey JM. Comparison of TaqMan and SYBR green qPCR methods for quantitative gene expression in tung tree tissues. J Agric Food Chem. 2012;60:12296-303. https://doi.org/10.1021/jf304690e.

40. Von Der Mark K, Gauss V, Von Der Mark H, MÜLler P. Relationship between cell shape and type of collagen synthesised as chondrocytes lose their cartilage phenotype in culture. Nature. 1977;267:531. https:// doi.org/10.1038/267531a0.

41. Foldager CB, Gomoll AH, Lind M, Spector M. Cell seeding densities in autologous chondrocyte implantation techniques for cartilage repair. Cartilage. 2012;3:108-17. https://doi.org/10.1177/1947603511435522.

42. Pietschmann MF, Horng A, Niethammer T, Pagenstert I, Sievers B, Jansson V, Glaser C, Muller PE. Cell quality affects clinical outcome after MACl procedure for cartilage injury of the knee. Knee Surg Sports Traumatol Arthrosc. 2009;17:1305-11. https://doi.org/10.1007/s00167-009-0828-7.

43. Aurich M, Squires GR, Reiner A, Mollenhauer JA, Kuettner KE, Poole AR, Cole AA. Differential matrix degradation and turnover in early cartilage lesions of human knee and ankle joints. Arthritis Rheum. 2005;52:112-9.

44. Rolauffs B, Williams JM, Grodzinsky AJ, Kuettner KE, Cole AA. Distinct horizontal patterns in the spatial organization of superficial zone chondrocytes of human joints. J Struct Biol. 2008;162:335-44. https://doi. org/10.1016/j.jsb.2008.01.010.

45. Aicher WK, Rolauffs B. The spatial organisation of joint surface chondrocytes: review of its potential roles in tissue functioning, disease and early, preclinical diagnosis of osteoarthritis. Ann Rheum Dis. 2014;73:645-53. https://doi.org/10.1136/annrheumdis-2013-204308.

46. Felka T, Rothdiener M, Bast S, Uynuk-Ool T, Zouhair S, Ochs BG, De Zwart P, Stoeckle U, Aicher WK, Hart ML, Shiozawa T, Grodzinsky AJ, Schenke-Layland K, Venkatesan JK, Cucchiarini M, Madry H, Kurz B, Rolauffs B. Loss of spatial organization and destruction of the pericellular matrix in early osteoarthritis in vivo and in a novel in vitro methodology. Osteoarthr Cartil. 2016;24: 1200-9. https://doi.org/10.1016/j.joca.2016.02.001.

47. Jackson DW, Simon TM. Chondrocyte transplantation. Arthroscopy. 1996:12:732-8.

48. Bekkers JE, Saris DB, Tsuchida Al, van Rijen MH, Dhert WJ, Creemers LB. Chondrogenic potential of articular chondrocytes depends on their original location. Tissue Eng A. 2014;20:663-71. https://doi.org/10.1089/ ten.TEA.2012.0673.

49. Malicev E, Barlic A, Kregar-Velikonja N, Strazar K, Drobnic M. Cartilage from the edge of a debrided articular defect is inferior to that from a standard donor site when used for autologous chondrocyte cultivation. J Bone Joint Surg Br. 2011;93:421-6. https://doi.org/10.1302/0301-620X.93B3.25675.

50. Giannini S, Buda R, Grigolo B, Vannini F, De Franceschi L, Facchini A. The detached osteochondral fragment as a source of cells for autologous chondrocyte implantation (ACI) in the ankle joint. Osteoarthr Cartil. 2005;13: 601-7. https://doi.org/10.1016/j.joca.2005.02.010.

\section{Ready to submit your research? Choose BMC and benefit from:}

- fast, convenient online submission

- thorough peer review by experienced researchers in your field

- rapid publication on acceptance

- support for research data, including large and complex data types

- gold Open Access which fosters wider collaboration and increased citations

- maximum visibility for your research: over $100 \mathrm{M}$ website views per year

At BMC, research is always in progress.

Learn more biomedcentral.com/submissions 